\title{
An experimental combination of IGS repro3 campaign's orbit products using a variance component estimation strategy
}

\author{
Pierre Sakic • Gustavo Mansur • \\ Benjamin Männel • Andreas Brack • \\ Harald Schuh
}

Received: date / Accepted: date

Nota Bene: This manuscript has been submitted for publication in International Association of Geodesy Symposia proceedings. Please note that this manuscript has yet to be formally accepted for publication. Subsequent versions of this manuscript may have slightly different content. If accepted, the final version of this manuscript will be available via the Peer-reviewed Publication DOI link on the right-hand side of the EarthArXiv webpage. Please feel free to contact any of the authors; we welcome feedback.

\begin{abstract}
Over the past years, the International GNSS Service (IGS) has put efforts into reprocessing campaigns reanalyzing the full data collected by the IGS network since 1994. The goal is to provide a consistent set of orbits, station coordinates, and earth rotation parameters using state-of-the-art models. Different from the previous campaigns - namely: repro1 and repro2 - the repro3 includes not only GPS and GLONASS but also the Galileo constellation. The main repro3 objective is the contribution to the next realization of the International Terrestrial Reference Frame (ITRF2020). To achieve this goal, several Analysis Centers (AC) submitted their specific products, which are combined to provide the final solutions for each product type. In this contribution, we focus on the combination of the orbit products. We will present a consistent orbit solution based on a newly developed combination strategy where the weights are determined by a Least-Squares Variance Component Estimation (LSVCE). The orbits are combined in an iterative processing, first aligning all the products via a Helmert transformation, second defining which satellites will be used in the LSVCE, and finally normalizing the inverse of the variances as weights that are used to compute a weighted mean. Moreover, we

P. Sakic · B. Männel · A. Brack · H. Schuh GFZ German Research Centre for Geosciences, Helmholtz-Zentrum Potsdam, Potsdam, Germany

E-mail: pierre.sakic@gfz-potsdam.de·G. Mansur.H. Schuh

Technische Universität Berlin, Institute for Geodesy and Geoinformation Technology, Faculty VI, Berlin, Germany
\end{abstract}


will discuss the weight factors and their stability in the time evolution for each $\mathrm{AC}$ depending on the constellations. In addition, an external validation using a Satellite Laser Ranging (SLR) procedure will be shown for the combined solution.

Keywords GNSS · IGS · Repro3 · Variance Components Estimation · Orbit combination

\section{Introduction}

Over the past years, the International GNSS Service (IGS) has put efforts into reprocessing campaigns reanalyzing the full data collected by the IGS network since 1994. The goal is to provide a consistent set of orbits, station coordinates, and earth rotation parameters using state-of-the-art models. Since the end of 2020, the IGS has completed the reprocessing 3 campaign (abbreviated as repro3). It differs from the previous campaigns (namely repro1 achieved in 2009 and repro 2 in 2015) by the fact that repro3 includes not only GPS and GLONASS but also the Galileo constellation. The main repro3 objective is to provide the GNSS contribution to the next realization of the International Terrestrial Reference Frame (ITRF2020, Altamimi et al., 2021). To achieve this goal, 12 Analysis Centers (AC) joined the effort and submitted their specific products to the Analysis Center Coordinator (ACC). Each product type is then combined at the solution or at the normal equation level to provide to the final user an "IGS-labeled" solution with the best accuracy possible. In this contribution, we mainly focus on the combination of the orbit products.

The strategy of combining orbits and clock offsets was developed during the early age of the IGS for two main reasons (Kouba et al., 1994):

1. to provide to the users the most reliable of all the submitted solutions and

2. to offer a feedback tool to evaluate the consistency between ACs.

The initial developments of such combination were performed by Springer and Beutler (1993) and Beutler et al. (1995), and then slightly modified by Kouba et al. (2001). However, it has evolved very little for more than 25 years. The major limitation of the current algorithm used operationally by the IGS's ACC is that it is not adapted to a multi-GNSS environment (Mansur et al., 2020b), while the new generation of satellite positioning constellations (Galileo, Beidou, QZSS, IRNSS) are coming to maturity. Therefore, an update of the combination procedure is necessary.

Thus, our research group has started to study a new combination strategy compatible with the new constellations, initially based on the legacy IGS software (Sakic et al., 2020), then by designing an ad hoc strategy optimised for a multi-GNSS configuration (Mansur et al., 2020b). These activities are carried out in parallel with the orbit combination studies performed by the ACC in the context of the IGS's Multi-GNSS Experiment (MGEX) pilot project (Sośnica et al., 2020), and the ones regarding integer clocks (Banville et al., 2020). 
The present paper presents the results obtained for an orbit combination of the IGS's repro3 orbit products based on the new strategy we developed. We describe hereafter the input products integrated and the processing method. We present the results of the orbit combination results compared with each individual AC, for all satellites and for each separated constellation. We provide also a Satellite Laser Ranging (SLR) validation for an external assessment of the combination.

\section{Material and methods}

The new combination strategy is based on a Least-Squares Variance Component Estimation (LSVCE) weighting and developed within the framework of the GeodeZYX Toolbox (Sakic et al., 2019). The method is described in detail in Mansur et al. (2020a). The general workflow can be summarized as follow:

1. A gross mean of all the input AC's orbits is computed.

2. Helmert transformations are performed between this mean and the ACs' solutions.

3. A set of so-called "core satellites" is defined. The goal is to get the common satellites present in all the input AC's solutions. During this step, an improved outlier detection scheme is applied: a Modified Z-Score approach (Iglewicz and Hoaglin, 1993) is used to test the radial, along-track, and cross-track components of each set of AC coordinates for all satellites. If one satellite's component is detected as outlier, the satellite is excluded from the set of core satellites.

4. The variance components are estimated based on the theory of AmiriSimkooei et al. (2007), using only the set of core satellites as defined before.

5 . The variance components $\sigma^{2}$ are normalized and used as weights using the formula:

$$
\hat{\mathbf{X}}_{\mathrm{c}}=\frac{1}{\sum_{a c=1}^{A C} \frac{1}{\sigma_{a c}^{2}}} \cdot \sum_{a c=1}^{A C} \frac{1}{\sigma_{a c}^{2}} \cdot \overline{\mathbf{X}}_{r},
$$

Where $\overline{\mathbf{X}}_{r}$ are the input coordinate vectors of the ACs, $\sigma_{a c}^{2}$ is the variance for each $\mathrm{AC}$, and $\hat{\mathbf{X}}_{\mathrm{c}}$ is the combined coordinate vector.

The process is repeated iteratively until the 3D-RMS difference between two iterations is bellow $1 \mathrm{~mm}$. This occurs usually at the fifth iteration.

The algorithm has been designed to realize a weighting based on the different $\mathrm{AC}$ only, or based on both the ACs and the different constellations. For the present study, we adopted the so-called AC plus constellation strategy.

We considered all the orbit products provided by the different ACs which participated to the repro3 efforts. The campaign period ranges from GPS week 730 (1994-01-02) to 2138 (2020-12-31). Table 1 summarizes the different AC products used and their contribution period.

The orbits are described in the SP3d format (Hilla, 2016) and were retrieved from the CDDIS server (Noll, 2010). 


\begin{tabular}{|l|l|l|l|l|l|}
\hline Analysis Center & Abrev. & Const. & $\begin{array}{l}\text { First epoch } \\
\text { (calendar) }\end{array}$ & $\begin{array}{l}\text { First epoch } \\
\text { (GPS week) }\end{array}$ & Product and/or software \\
\hline CODE & code & GRE & $1994-01-02$ & 730 & $\begin{array}{l}\text { Selmke et al. (2020) } \\
\text { Dach et al. (2015) }\end{array}$ \\
\hline ESA/ESOC & esa & GRE & $1995-01-01$ & 782 & Schoenemann et al. (2021) \\
\hline GFZ & gfz & GRE & $1994-01-02$ & 730 & Männel et al. (2020, 2021) \\
\hline GRGS/CNES/CLS & grg & GRE & $2000-05-03$ & 1060 & Katsigianni et al. (2019) \\
\hline JPL & jpl & G & $1994-01-01$ & 729 & Bertiger et al. (2020) \\
\hline MIT & mit & GE & $2000-01-02$ & 1043 & Herring et al. (2018) \\
\hline NGS & ngs & G & $1994-01-02$ & 730 & Damiani and Freeman (2019) \\
\hline TU Graz & tug & GRE & $1994-01-01$ & 729 & $\begin{array}{l}\text { Strasser and Mayer-Gürr (2021) } \\
\text { Mayer-Gürr et al. (2021) }\end{array}$ \\
\hline Wuhan University & whu & GR & $2008-01-01$ & 1460 & Guo et al. (2016) \\
\hline
\end{tabular}

Table 1 Summary of the different input orbit products

\section{Results}

To evaluate the compatibility between the combination and the input orbit products, we compute the Root Mean Square (RMS) differences using the formulas described in Kouba et al. (1994). We also adopt a similar graphical representation as the one usually presented by the IGS's ACC (e.g. Griffiths, 2019): dots representing the daily RMS, and a smoothing curve based on a 14-day window Gaussian filter. We perform also a comparison with respect to the previous combined orbits generated at the end of the previous repro2 campaign (Griffiths, 2019). The results are shown in Figure 3. The repro2 products, used only for comparison purposes, are identified as rp2 in Figure 3.

For GPS, differences of individual ACs with respect to the combination reach $60 \mathrm{~mm}$ for the early weeks of the repro3 period. It stabilizes after GPS week 1400 at around $25 \mathrm{~mm}$ for the ACs with the highest RMS, and around $10 \mathrm{~mm}$ for the majority of the ACs. The best RMS values along with the best stability is achieved by the TU Graz solution around $6 \mathrm{~mm}$. A noticeable difference with the repro2 solution is visible, ranging from $18 \mathrm{~mm}$ for the early weeks to $10 \mathrm{~mm}$ after GPS week 1250 . This difference can be seen as a general improvement in the accuracy of the repro3 orbits compared to the previous reprocessing campaign.

For GLONASS, the difference is centered around $30 \mathrm{~mm}$ for the complete period, with a dispersion between $55 \mathrm{~mm}$ and $20 \mathrm{~mm}$, achieved by ESA and CODE. Regarding Galileo, the difference ranges from ca. $35 \mathrm{~mm}$ from GPS week 1745 (date of the first Galileo satellite activation) to a stabilized value of $16 \mathrm{~mm}$ after GPS week 1900. For the European constellation, it is also remarkable that half of the ACs (namely CODE, ESA and TU Graz) agree on similar orbits since their RMS differences with respect to the combination is the same.

The weights derived from the LSVCE are represented on Figure 3. They are the corollary of the RMS difference plots, since the ACs with the smallest RMS present the highest weights. 


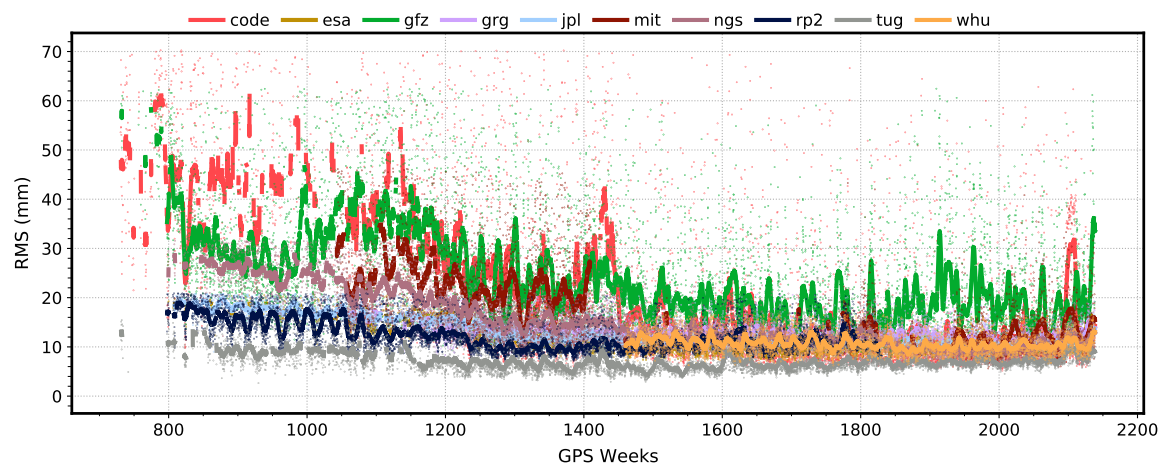

(a) GPS

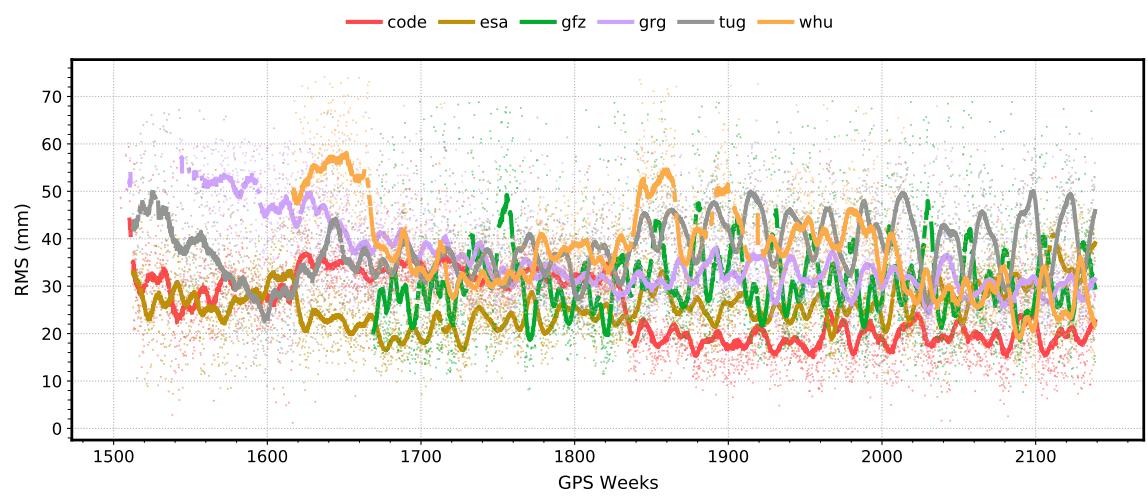

(b) GLONASS

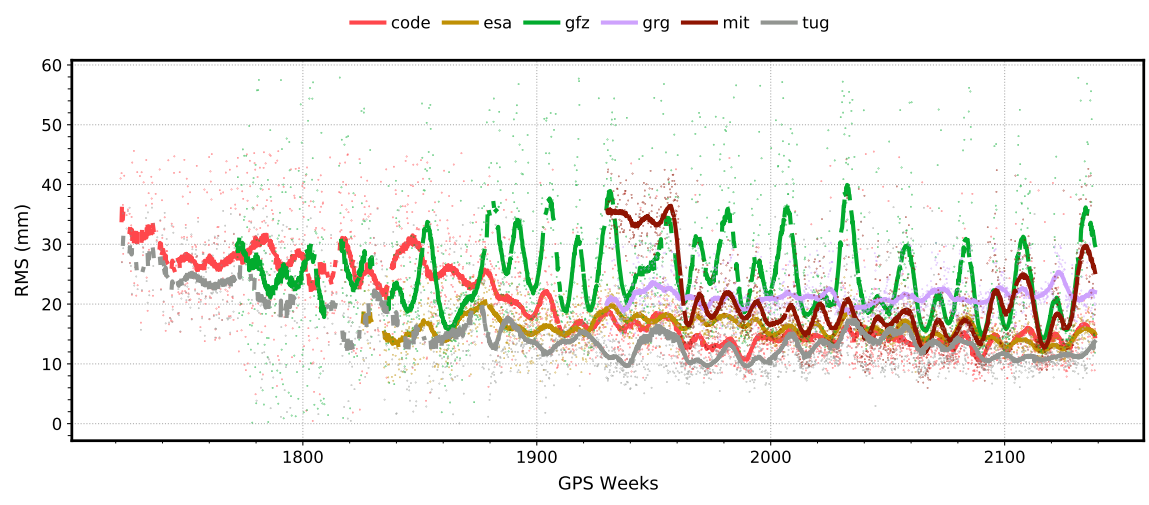

(c) Galileo

Fig. 1 3D-RMS difference of individual AC orbit solutions w.r.t the combined solution Please note that the y-axis scales are different for each figure. 


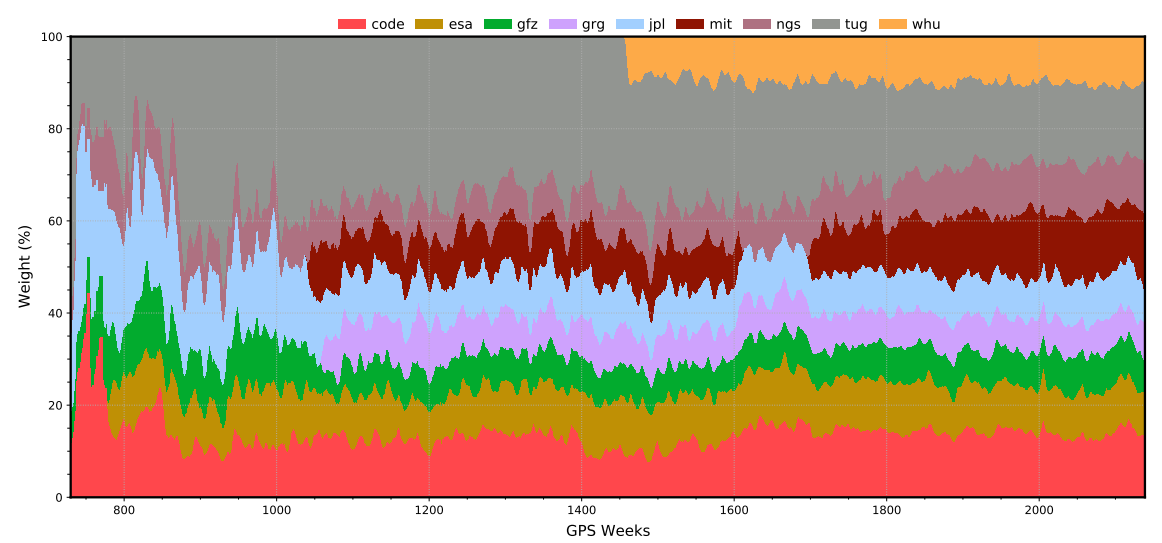

(a) GPS

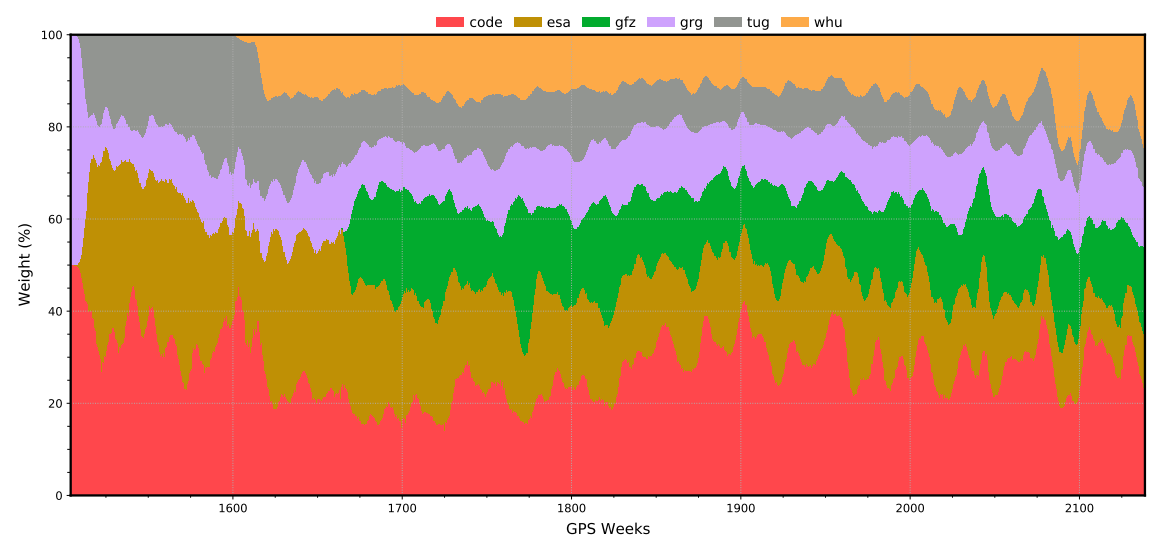

(b) GLONASS

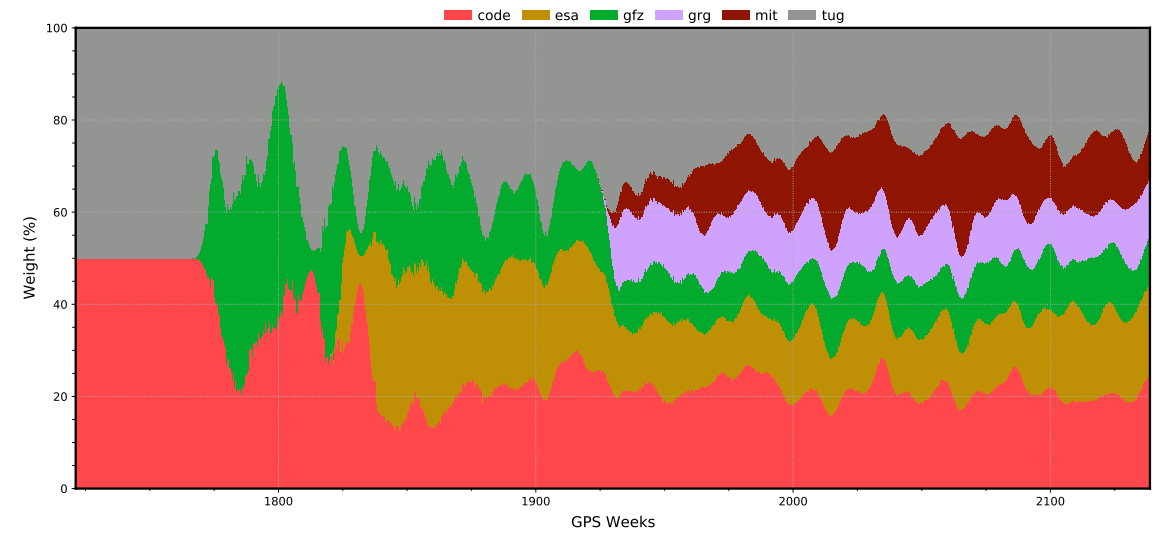

(c) Galileo

Fig. 2 Weights derived from the LSVCE for each AC solution per constellation 


\section{SLR external validation}

To perform an independent quality assessment of the combination, we performed an external validation using SLR observations. Indeed, all Galileo and the current GLONASS satellites are equipped with Laser Retroreflector Arrays (LRA, Dell'Agnello et al., 2011) and thus are suited for such operation. We use as observation input the normal points provided by the International Laser Ranging Service (ILRS, Pearlman et al., 2002). The processing is performed with GFZ's EPOS-P8 software (Uhlemann et al., 2015), designed for GNSS precise orbit determination, precise point positioning, and SLR residual estimation. SLR station coordinates are fixed to the SLRF2014 (Luceri et al., 2015). Ocean tidal loading is corrected from the station positions using the FES2004 model (Lyard et al., 2006). An outlier threshold for residuals over $0.5 \mathrm{~m}$ is applied. Daily averaged residuals are shown in Figure 4. The validation is performed starting from GPS week 1745, when the first Galileo satellites were available. Table 2 summarizes the mean residuals and the associated standard deviation for each AC and both constellations.

\begin{tabular}{llrr} 
Const. & AC & Mean & Std. \\
\hline R & cod & 0.04 & 9.61 \\
R & esa & 1.26 & 8.89 \\
R & gfz & 0.79 & 16.47 \\
R & grgs & 7.67 & 9.15 \\
R & tug & -5.03 & 9.14 \\
R & whu & 3.54 & 23.13 \\
R & repro3 & 0.84 & 9.10 \\
\hline E, full & cod & -6.31 & 13.08 \\
E, full & esa & -5.84 & 8.58 \\
E, full & gfz & -14.37 & 14.69 \\
E, full & grgs & 21.34 & 8.53 \\
E, full & mit & -0.12 & 10.97 \\
E, full & tug & 2.37 & 22.87 \\
E, full & repro3 & -2.63 & 14.56 \\
\hline E, red. & cod & -4.26 & 8.42 \\
E, red. & esa & -6.58 & 7.15 \\
E, red. & gfz & -14.16 & 12.25 \\
E, red. & grgs & 21.34 & 8.53 \\
E, red. & mit & -0.12 & 10.97 \\
E, red. & tug & 10.84 & 8.65 \\
E, red. & repro3 & 1.55 & 8.15 \\
\hline
\end{tabular}

Table 2 Mean residuals and standard deviation in $\mathrm{mm}$ for each input AC for GLONASS (R) and Galileo (E). For Galileo, the statistics are split into two ranges: a full period ("E, full" column) and a reduced period ("E, red." column) starting from GPS week 1890.

The combined solution shows one of the best agreements with the SLR measurement (-2.63 mm mean residuals for Galileo, 0.84 mm for GLONASS). It shows also the second smallest dispersion for GLONASS $(\sigma=9.10 \mathrm{~mm}$ for GLONASS). For Galileo, the combination dispersion is not significantly reduced over the whole tested period ("E, full" in Table 2) due to the input 


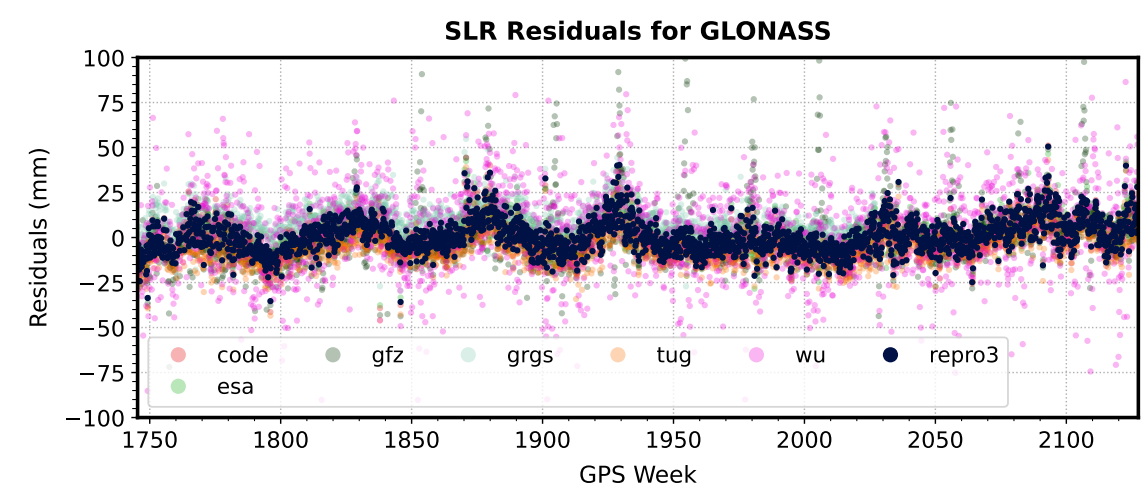

(a) GLONASS

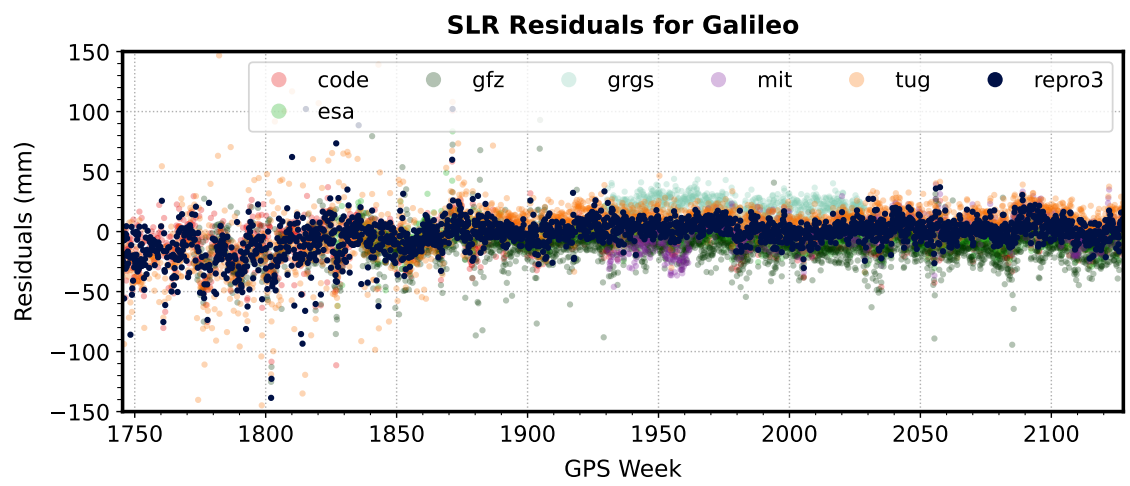

(b) Galileo

Fig. 3 Average SLR Residuals per constellation for each AC solution and the combination

solutions' high residuals during the early weeks. But if we consider the residuals on a reduced period only after the GPS week 1890 ("E, red." in Table 2), the combination shows the second smallest dispersion. This external validation illustrates that the combination provides both the best accuracy and precision level out of the individual input solutions.

\section{Discussion and perspectives}

We developed a new GNSS orbit combination strategy based on a LeastSquares Variance Component Estimation, and an improved detection for outlier satellites. This algorithm can also handle the different constellations separately. It corrects the weaknesses of the legacy software used routinely by the IGS's ACC, which have been raised during a preliminary study investigating the possibilities to improve it for a multi-GNSS environment (Sakic et al., 
2020). We tested this new algorithm with the recent set of orbit products generated by the different IGS ACs in the framework of the repro3 reprocessing campaign. A $10 \mathrm{~mm}$ internal precision is achieved for GPS, $30 \mathrm{~mm}$ for GLONASS, and $16 \mathrm{~mm}$ for Galileo. The SLR validation shows that the combination has one of the best agreements with the laser measurements and also the smallest residual dispersion, then confirming its robustness with an external technique. The results can be a useful tool for the ACs to identify potential weaknesses in their processing. The present work can also be a support for cross-comparison and validation of the orbit combination currently performed by the IGS's ACC (Masoumi and Moore, 2021).

Acknowledgements We would like to thank the International Laser Ranging Service (ILRS), the International GNSS Service and more particularly its Analysis Centers for providing their products. The PhD of Gustavo Mansur is funded by the Deutscher Akademischer Austauschdienst (DAAD, German Academic Exchange Service).

\section{References}

Altamimi Z, Rebischung P, Métivier L, Collilieux X, Chanard K (2021) Highlights of IGS Contribution to ITRF2020. In: Tour de l'IGS 1st Stop online conference, URL https://files.igs.org/pub/resource/pubs/workshop/2021/03-Altamimi.pdf

Amiri-Simkooei AR, Tiberius CC, Teunissen PJ (2007) Assessment of noise in GPS coordinate time series: Methodology and results. Journal of Geophysical Research: Solid Earth 112(7):1-19, DOI 10.1029/2006JB004913

Banville S, Geng J, Loyer S, Schaer S, Springer T, Strasser S (2020) On the interoperability of IGS products for precise point positioning with ambiguity resolution. Journal of Geodesy 94(1):10, DOI 10.1007/s00190-019-01335-w, URL https://doi.org/10.1007/s00190019-01335-w http://link.springer.com/10.1007/s00190-019-01335-w

Bertiger W, Bar-Sever Y, Dorsey A, Haines B, Harvey N, Hemberger D, Heflin M, Lu W, Miller M, Moore AW, Murphy D, Ries P, Romans L, Sibois A, Sibthorpe A, Szilagyi B, Vallisneri M, Willis P (2020) GipsyX/RTGx, a new tool set for space geodetic operations and research. Advances in Space Research 66(3):469-489, DOI 10.1016/j.asr.2020.04.015, URL https://doi.org/10.1016/j.asr.2020.04.015, 2004.13124

Beutler G, Kouba J, Springer T (1995) Combining the orbits of the IGS Analysis Centers. Bulletin Géodésique 69(4):200-222, DOI 10.1007/BF00806733, URL http://link.springer.com/10.1007/BF00806733

Dach R, Lutz S, Walser P, Fridez P (2015) Bernese GNSS Software Version 5.2 DOI 10.7892/BORIS.72297, URL https://boris.unibe.ch/72297/

Damiani T, Freeman W (2019) Strengthening the NOAA CORS Network: Foundation CORS, Orbit Analysis, and Other Initiatives. In: AGU Fall Meeting Abstracts, vol 2019, pp G11A-07

Dell'Agnello S, Delle Monache GO, Currie DG, Vittori R, Cantone C, Garattini M, Boni A, Martini M, Lops C, Intaglietta N, Tauraso R, Arnold DA, 
Pearlman MR, Bianco G, Zerbini S, Maiello M, Berardi S, Porcelli L, Alley CO, McGarry JF, Sciarretta C, Luceri V, Zagwodzki TW (2011) Creation of the new industry-standard space test of laser retroreflectors for the GNSS and LAGEOS. Advances in Space Research 47(5):822-842, DOI 10.1016/j.asr.2010.10.022

Griffiths J (2019) Combined orbits and clocks from IGS second reprocessing. Journal of Geodesy 93(2):177-195, DOI 10.1007/s00190-018-1149-8, URL http://link.springer.com/10.1007/s00190-018-1149-8

Guo J, Xu X, Zhao Q, Liu J (2016) Precise orbit determination for quadconstellation satellites at Wuhan University: strategy, result validation, and comparison. Journal of Geodesy 90(2):143-159, DOI 10.1007/s00190-0150862-9

Herring TA, King RW, Floyd MA, McClusky SC (2018) GAMIT Reference Manual - Release 10.7. Department of Earth, Atmospheric, and Planetary Sciences Massachusetts Institute of Technology

Hilla S (2016) The Extended Standard Product 3 Orbit Format (SP3-d). Tech. rep., National Geodetic Survey, Silver Spring, URL ftp://ftp.igs.org/pub/data/format/sp3d.pdf

Iglewicz B, Hoaglin DC (1993) How to detect and handle outliers, vol 16. Asq Press

Katsigianni G, Loyer S, Perosanz F, Mercier F, Zajdel R, Sośnica K (2019) Improving Galileo orbit determination using zero-difference ambiguity fixing in a Multi-GNSS processing. Advances in Space Research 63(9):2952-2963, DOI 10.1016/j.asr.2018.08.035

Kouba J, Mireault Y, Lahaye F (1994) IGS orbit/clock combination and evaluation, Appendix 1 of the analysis coordinator report, international GPS Service For Geodynamics 1994 Annual Report. Jet Propulsion Laboratory publication pp 18-95

Kouba J, Springer T, Héroux P (2001) New IGS Station and Satellite Clock Combination. GPS Solutions 4(4):31-36, DOI 10.1007/PL00012863, URL http://link.springer.com/10.1007/PL00012883

Luceri V, Pavlis EC, Pace B, König D, Kuzmicz-Cieslak M, Bianco G (2015) Overview of the ILRS Contribution to the Development of ITRF2013. In: International Association of Geodesy Symposia, pp 101-108, DOI 10.1007/1345_2015_153, URL http://link.springer.com/10.1007/1345 2015153

Lyard F, Lefevre F, Letellier T, Francis O (2006) Modelling the global ocean tides: Modern insights from FES2004. Ocean Dynamics 56(5-6):394-415, DOI 10.1007/s10236-006-0086-x

Männel B, Brandt A, Bradke M, Sakic P, Brack A, Nischan T (2020) Status of IGS Reprocessing Activities at GFZ. In: International Association of Geodesy Symposia, Springer, Berlin, Heidelberg, DOI 10.1007/1345 ${ }_{2} 020_{9} 8$, URLhtp : //link.springer.com/10.1007/1345 $020_{9} 8$

Männel B, Brandt A, Bradke M, Sakic P, Brack A, Nischan T (2021) GFZ repro3 product series for the International GNSS Service (IGS). DOI 10.5880/GFZ.1.1.2021.001, URL https://dataservices.gfz- 
potsdam.de/panmetaworks/showshort.php?id=c7c804cc-6644-11eb-9603497c92695674

Mansur G, Sakic P, Brack A, Männel B, Schuh H (2020a) Combination of GNSS orbits using variance component estimation. In review in Journal of Geodesy pp $1-12$

Mansur G, Sakic P, Männel B, Schuh H (2020b) Multi-constellation GNSS orbit combination based on MGEX products. Advances in Geosciences 50:57-64, DOI 10.5194/adgeo-50-57-2020, URL https://www.advgeosci.net/50/57/2020/ https://adgeo.copernicus.org/articles/50/57/2020/

Masoumi S, Moore M (2021) Multi-GNSS orbit solutions from the third IGS Reprocessing. In: Tour de l'IGS 1st Stop online conference, URL https://files.igs.org/pub/resource/pubs/workshop/2021/04-Masoumi.pdf

Mayer-Gürr T, Behzadpour S, Eicker A, Ellmer M, Koch B, Krauss S, Pock C, Rieser D, Strasser S, Süsser-Rechberger B, Zehentner N, Kvas A (2021) GROOPS: A software toolkit for gravity field recovery and GNSS processing. Computers and Geosciences 155(December 2020):104864, DOI 10.1016/j.cageo.2021.104864, URL https://doi.org/10.1016/j.cageo.2021.104864

Noll CE (2010) The crustal dynamics data information system: A resource to support scientific analysis using space geodesy. Advances in Space Research 45(12):1421-1440, DOI 10.1016/j.asr.2010.01.018, URL https://linkinghub.elsevier.com/retrieve/pii/S0273117710000530

Pearlman M, Degnan J, Bosworth J (2002) The International Laser Ranging Service. Advances in Space Research 30(2):135-143, DOI 10.1016/S0273-1177(02)00277-6, URL http://ebooks.worldscinet.com/ISBN/9789812836182/9789812836182 0009 .htmlhttps : //linkinghub.elsevier.com/retrieve/pii/S0273117702002776

Sakic P, Mansur G, Kitpracha C, Ballu V (2019) The geodeZYX toolbox: a versatile Python 3 toolbox for geodetic-oriented purposes. DOI 10.5880/GFZ.1.1.2019.002, URL http://dataservices.gfzpotsdam.de/panmetaworks/showshort.php?id=escidoc: 4754924

Sakic P, Mansur G, Mannel B (2020) A prototype for a MultiGNSS orbit combination. In: 2020 European Navigation Conference (ENC), IEEE, pp 1-11, DOI 10.23919/ENC48637.2020.9317316, URL https://ieeexplore.ieee.org/document/9317316/

Schoenemann E, Dilssner F, Mayer V, Gini F, Otten M, Springer T, Bruni S, Enderle W, Zandbergen R (2021) ESA's efforts for more consistent geodetic products. EGU General Assembly 2021 DOI 10.5194/egusphere-egu21-8899, URL https://doi.org/10.5194/egusphere-egu21-8899

Selmke I, Dach R, Arnold D, Prange L, Schaer S, Sidorov D, Stebler P, Villiger A, Jäggi A, Hugentobler U (2020) CODE repro3 product series for the IGS DOI 10.7892/BORIS.135946, URL https://boris.unibe.ch/135946/

Sośnica K, Zajdel R, Bury G, Bosy J, Moore M, Masoumi S (2020) Quality assessment of experimental IGS multi-GNSS combined orbits. GPS Solutions 24(2):54, DOI 10.1007/s10291020-0965-5, URL https://doi.org/10.1007/s10291-020-0965-5 
http://link.springer.com/10.1007/s10291-020-0965-5

Springer T, Beutler G (1993) Towards an official IGS orbit by combining the results of all IGS Processing Centers. In: Proceedings of the 1993 IGS Workshop, held March, pp 24-26

Strasser S, Mayer-Gürr T (2021) Satellite orbits. DOI 10.3217/DATASET-70126314-1426, URL https://repository.tugraz.at/records/ebamh-r3860

Uhlemann M, Gendt G, Ramatschi M, Deng Z (2015) GFZ Global MultiGNSS Network and Data Processing Results. In: International Association of Geodesy Symposia, vol 12, Springer, pp 673-679, DOI 10.1007/1345 $2015_{1} 20$, URLhttp : //link.springer.com/10.1007/1345 $2015_{1} 20$ 